\title{
PRIMARY ANALYSIS OF THE TRAJECTORY OF FLOATING PARTICLES IN A COMPOUND CHANNEL
}

\author{
Marcin Krukowski ${ }^{\bowtie}$, Piotr Siwicki \\ Institute of Environmental Engineering, Faculty of Civil and Environmental Engineering, Warsaw University of Life \\ Sciences-SGGW, ul. Nowoursynowska 159, 02-776 Warsaw
}

\begin{abstract}
Aim of the study

The aim of the study was to determine the parameters of the stream transport capacity using turbulent diffusion coefficients using the imaging technique and to compare them with the coefficients obtained as a result of the measurement with the ADV (acoustic Doppler velocimeter) probe in a compound channel.
\end{abstract}

\begin{abstract}
Materials and methods
Model tests were carried out on a physical concrete model of a straight open channel with symmetrically complex trapezoidal cross section. On the model, the study of particle motion was carried out using the digital image recording technique with the analysis of the motion of the dosed indicator (solid particles), (PIV) (Particle Image Velocimetry), allowing to determine the basic parameters characterizing the process of their transport in the subsurface layer of water in the channel.
\end{abstract}

\section{Results and conclusions}

Primary analysis of test results obtained in laboratory conditions using the PIV (Particle Image Velocimetry) technique based on particle trajectory (in Lagrange's approach), in comparison with the results of calculations of turbulence characteristics based on measurements with the ADV probe (in Euler's approach), show significant differences between the results obtained. Turbulence intensity, vortex length, and values of turbulent diffusion coefficients, calculated on the basis of Lagrange's autocorrelation function, are much higher than the values calculated according to Euler's function.

Keywords: trajektory of floating particles, compound channel

\section{INTRODUCTION}

Hydraulic flow conditions in a compound channel cross-section, i.e. one with a significantly changing depth along its width, are shaped by the varying roughness of the bottom and slopes, and the exchange and momentum of water masses, between slower flowing water in the shallower floodplain, and faster flowing water in the deeper main channel. The exchange of water momentum between flows in the main channel and the floodplains affects the nature of the flow and, consequently, impacts the transport of masses of any admixtures in bipartite channels (Knight et al., 1994; Rowiński et al., 2002; Sofialdis and Prinos, 1999).

Explanation of processes occurring during the flow of water in a channel with a compound cross-section is possible by learning its kinematic and turbulent structure. One of the possible new methods of visualizing the flow in a channel with a compound cross-section is

凶e-mail: marcin_krukowski@sggw.pl 
introducing an index into the flow area, which quickly spreads to the entire area occupied by moving water, resulting in its homogeneous concentration. The propagation rate of the index depends on many factors, but the fundamental one is the structure of the pulsation speed of water particles. The only way to describe turbulent flow is the statistical description, with hydrodynamic quantities occurring in it being random in time and space.

\section{THEORETICAL FOUNDATIONS}

A particle floating on the water surface reacts to random speed changes, and moves with water in a manner depending on the structure of water turbulence. A detailed description of particle motion requires the use of a particle motion equation, for instance, in the version proposed by Tchen (Hinze, 1975). It was assumed that by using small particles with very low concentrations in the research, the hydraulic conditions of the water flow would not be disturbed, known as "unidirectional coupled" (Elghobashi, 1994). It is assumed that the particle shift is a direct result of water turbulence in the surface zone. The results of measurements of the solid particle path were interpreted based on the turbulent diffusion theory formulated by Taylor (1921) describing the propagation of heat and substances dissolved in water. It assumes validity of Fick's theory, according to which the particles remain in local equilibrium with the surrounding water. Therefore it is possible to apply the diffusion equation. For homogeneous turbulence, such conditions mean that the particle relaxation time must be much greater than the integral of turbulence time scale, and much less than the particle diffusion time (Mols and Oliemans, 1998). With these assumptions, the motion of solid particles is statistically similar to Brownian motion.

The description of the transfer of small particles on the water surface is made using the Lagrange method (Kozioł and Krukowski 2010). It was assumed that the solid particle is small and does not differ in analysis from the water particle when it is introduced to the surface of the turbulent flow of water in the channel at time $t_{0}=0$. The particle moves at Euler's velocity of flowing water $u(X, t)$. By determining the displacement of the selected particle $\mathrm{x}$ in time $t=\tau$ as $X(x, \tau)$, we can formulate:

$$
X(x, \tau)=\int_{t_{0}}^{t_{0}+\tau} V(x, t) d t
$$

where:

$X=\left(X_{1}, X_{2}, X_{3}\right)$ are Euler's coordinates, $x=X\left(x, t_{0}\right)$ is Lagrange's coordinate of the water particle at time $t_{0}=0 ; X(x, t) n$ is a random vector of particle displacement $x ; V(x, t)$ is Lagrange's particle velocity vector, described by Euler's velocity vector: $V(x, t)=u(X(x, t), t)$.

The displacement vector is a random value and its determination requires knowledge of three probability density distributions $p\left(X \mid t, x, t_{0}\right)$ of the position of the selected particle $x$ in the place $X$ at time $t$. In the case of stationary and homogeneous turbulences, the distribution of the density function of the position of the water particle $p(X \mid x, t)$ can be represented by a normal distribution. Two main characteristics of the random displacement vector were considered: first-order and second-order momentum. The mean value of this vector can be expressed as:

$$
\overline{X(x, \tau)}=\int_{t_{0}}^{t_{0}+\tau} \overline{V(x, t)} d t
$$

and its turbulent fluctuation, as:

$$
X^{\prime}(x, t)=X(x, t)-\overline{X(x, t)}=\int_{0}^{t} V^{\prime}(x, s) d s
$$

where the second-order moment of random displacement is expressed by the velocity field characteristics (Monin and Yaglom, 1971):

$$
\left.K_{i j}(t)=\overline{X_{i}^{\prime}(t) X_{j}^{\prime}(t)}=\sqrt{u_{i}^{\prime 2} u_{j}^{\prime 2}}\right)^{0.5} 2 \int_{0}^{t}(t-s) R_{i j}^{L}(s) d s
$$

The second-order momentum values depend on time as well as on the form of the correlation function $R_{i j}^{L}(t)$, which, in a sense, is a "measure of memory" of turbulent flow and characterizes the structure of existing vortices and the degree of correlation of future velocities with the current values. The values of the autocorrelation function $R_{i j}^{L}(t)$ will tend to zero at long times, and to the value 1 when time is equal to zero. The time scale of this process is defined as follows: 


$$
T_{i}^{L}=\int_{0}^{\infty} R_{i i}^{L}(s) d s
$$

It is known as the Lagrangian time scale or the total diffusion scale. On this basis, the definitions of the Lagrangian scale or total length scale were derived:

$$
L_{i}^{L}=\sqrt{u_{i}^{2}} T_{i}^{L}
$$

The time scale $T^{L}$ is usually considered a measure of the time over which the average particle maintains its given direction of motion. The length of the scale $L_{i}^{L}$ is very much related to the size of the vortices occurring in the homogeneous turbulent flow (Rowiński et al., 2005).

The autocorrelation function $R_{i j}(t)$ assumes a value equal to one for time $t=0$ and tends towards zero with $t$ tending towards infinity. In both cases, i.e. $t=0$ or $t \rightarrow \infty$, the second-order momentum can be simplified to the following two forms:

- for times shorter than Lagrange's microscale, $T_{i}^{L}$

$$
D_{i i}(t)=\overline{u_{i}^{\prime 2}} t^{2}
$$

- for times longer than Lagrange's microscale, when $t>>T_{i}^{L}$

$$
D_{i i}(t)=2 \overline{u_{i}^{\prime 2}} T_{i} t
$$

Referring to Taylor's theory, it can be stated that this property is characteristic of molecular diffusion: for long times there is a similarity between turbulent and molecular diffusion, and after a sufficiently long time, the variance of the $D_{i i}(t)$ particles increases linearly with time at the velocity of $2 \overline{u_{i}^{\prime 2}} T_{i} t$. This velocity is a property of the turbulent flow field, but not of water, as in the case of molecular diffusion. The motion of each particle will not depend on the initial conditions of motion after this time. Equation (8) can be treated as a measure of the spread of a cloud of particles, introduced from a point source into turbulent flow. The product $u_{i}^{\prime 2} T_{i}$ is called the Lagrangian turbulent diffusion coefficient in the i-th direction. The turbulent diffusion coefficient in a homogeneous stationary turbulent flow is related to the variations of the probability density function as follows:

$$
\begin{gathered}
K_{i}=\frac{1}{2} \frac{d}{d t} D_{i i} \equiv \\
=\frac{1}{2} \frac{d}{d t} \sigma_{i}^{2}=\overline{u_{i}^{\prime 2}} \int_{0}^{\infty} R_{i i}(t) d t \\
i=x, y
\end{gathered}
$$

The above analyses show a similarity between the diffusion of a single water particle and the concentration of dopant and cloud of particles in turbulent flow. The turbulent diffusion coefficient calculated from equation (9) can be used in the diffusion equation to calculate the particle density distribution in turbulent flow.

\section{RESEARCH METHODOLOGY}

The tests were carried out in a concrete model of a rectilinear section of the channel, $16 \mathrm{~m}$ long and $2.08 \mathrm{~m}$ wide, with symmetrical floodplains of a complex trapezoidal cross-section. The longitudinal slope of the bottom of the main channel and floodplain was constant, and amounted to $0.5 \%$. The bottom of the main channel and floodplain was horizontal in cross-section. Diagram of the compound cross-section of the tested channel model is shown in Figure 1.

The surface of the bottom of the main channel was smooth, whereas the surfaces of slopes and floodplains had roughness. The values of Manning roughness coefficients in the channel determined under uniform flow conditions were equal to $n=0.011 \mathrm{~m}^{-1 / 3} \mathrm{~s}$ for the smooth bottom of the main channel, $n=0.018 \mathrm{~m}^{-1 / 3} \mathrm{~s}$ for the rough surface of the left floodplain, and $n=0.025 \mathrm{~m}^{-1 / 3} \mathrm{~s}$ for the right floodplain.

In the first stage of the study, we have determined the variability of the stream turbulence characteristics, calculated on the basis of the instantaneous values of the longitudinal velocity component in the verticals of the bipartite trapezoidal channel cross-section. Measurements of instantaneous velocity components were carried out in the main channel and in floodplains. The basic turbulence characteristics were calculated for the measured values of the longitudinal velocity component $v_{i}$ at selected points of the stream cross-section (Krukowski, 2005).

In the second stage of research, the transport capacity of the water stream in the channel was determined. The movement of solid particles floating on 


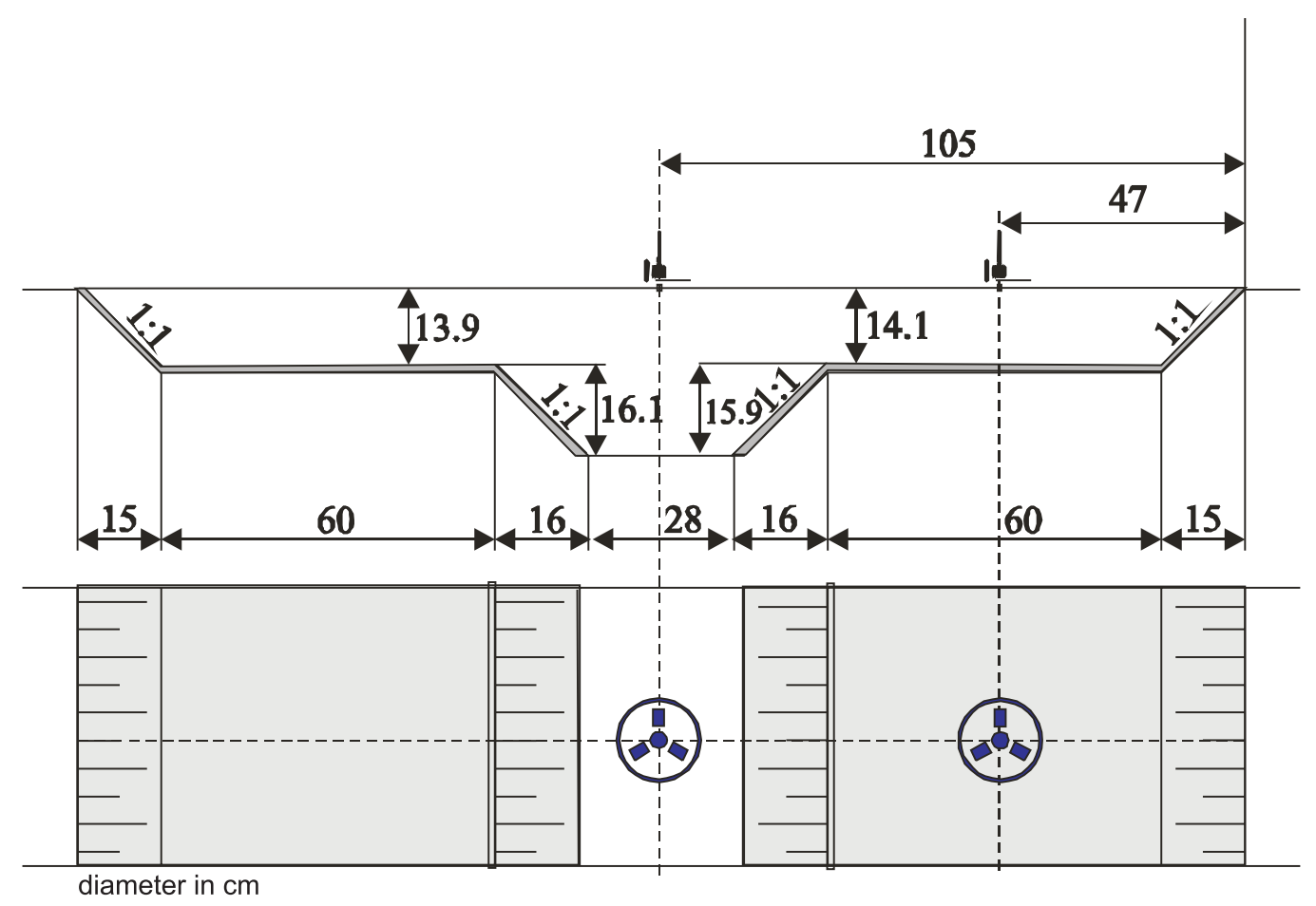

Fig. 1. Diagram of the cross-section of the channel, and the location of the dispenser in consecutive tests

the surface of the turbulent flow of water in the channel was recorded using digital cameras. The research assumption was that the particle size is small enough for it to have no significant impact on the process of particle transport.

Measurements were carried out for a stationary, point source of particles. The particles used in the study had the shape of a cylinder made of plastic (PVC). About 200 particles with a diameter of $10 \mathrm{~mm}$ and a thickness of $2 \mathrm{~mm}$ were prepared. For the introduction of particles, we designed and constructed a batcher that allowed the particles to be lowered onto the water surface at programmed constant intervals of time, varying from $1 \mathrm{~s}$ to $10 \mathrm{~s}$.

In the study of particle movement, the image recording technique with analysis of the motion of the dosed indicator was used (PIV - Particle Image Velocimetry), enabling the determination of basic parameters characterizing the process of their transport in the surface layer of water in the channel. Four digital cameras were used for this purpose. The cameras were mounted at the axis of the channel, at a height of $3.10 \mathrm{~m}$, so that the lenses of the 4 cameras covered a section of the channel with a length of $6.40 \mathrm{~m}$. The cameras were located at the following distances from the dispenser: $2.40 \mathrm{~m}, 3.90 \mathrm{~m}, 5.40 \mathrm{~m}$, and $6.90 \mathrm{~m}$, respectively (see: Fig. 2). A scaled grid of $0.10 \mathrm{~m}$ x $0.10 \mathrm{~m}$ with the main benchmark was placed in the field of view of each camera, enabling determination of the coordinates of the particle in the channel (see: Fig. 2). The grid enabled precise identification of the position of the dosed particles (see: Fig. 3 ). The knowledge of the grid's mesh size and the real span of the filmed scene allowed determining the metric span of the video image and determining the value of the ratio of the real-life proportionality to its recorded video image.

For the purpose of analysing the trajectory of the dosed indicator in the form of solid particles, their movement was recorded at two positions of the particle dispenser in cross-section (see: Fig. 1 and 2) for a determined flow rate in the channel (see: Table 1), in two selected parts of the complex channel (left floodplain and main channel). 195 particles were released 
Krukowski, M., Siwicki, P. (2019). Primary analysis of the trajectory of floating particles in a compound channel. Acta Sci. Pol., Formatio Circumiectus, 18 (4), 37-47. DOI: http://dx.doi.org/10.15576/ASP.FC/2019.18.4.37

in each dispenser position, of which a dozen or so particles were randomly selected for trajectory analysis. On the basis of the recorded video material, the location coordinates of the particles $\left(x_{i}, y_{i}\right)$ were determined, with the passage of dosing time since they were released (see: Table 1, Fig. 4). The coordinates of the particles position differed from each other due to the turbulent nature of the flow, and their random dispersion characterizes the transport capacity of the stream.

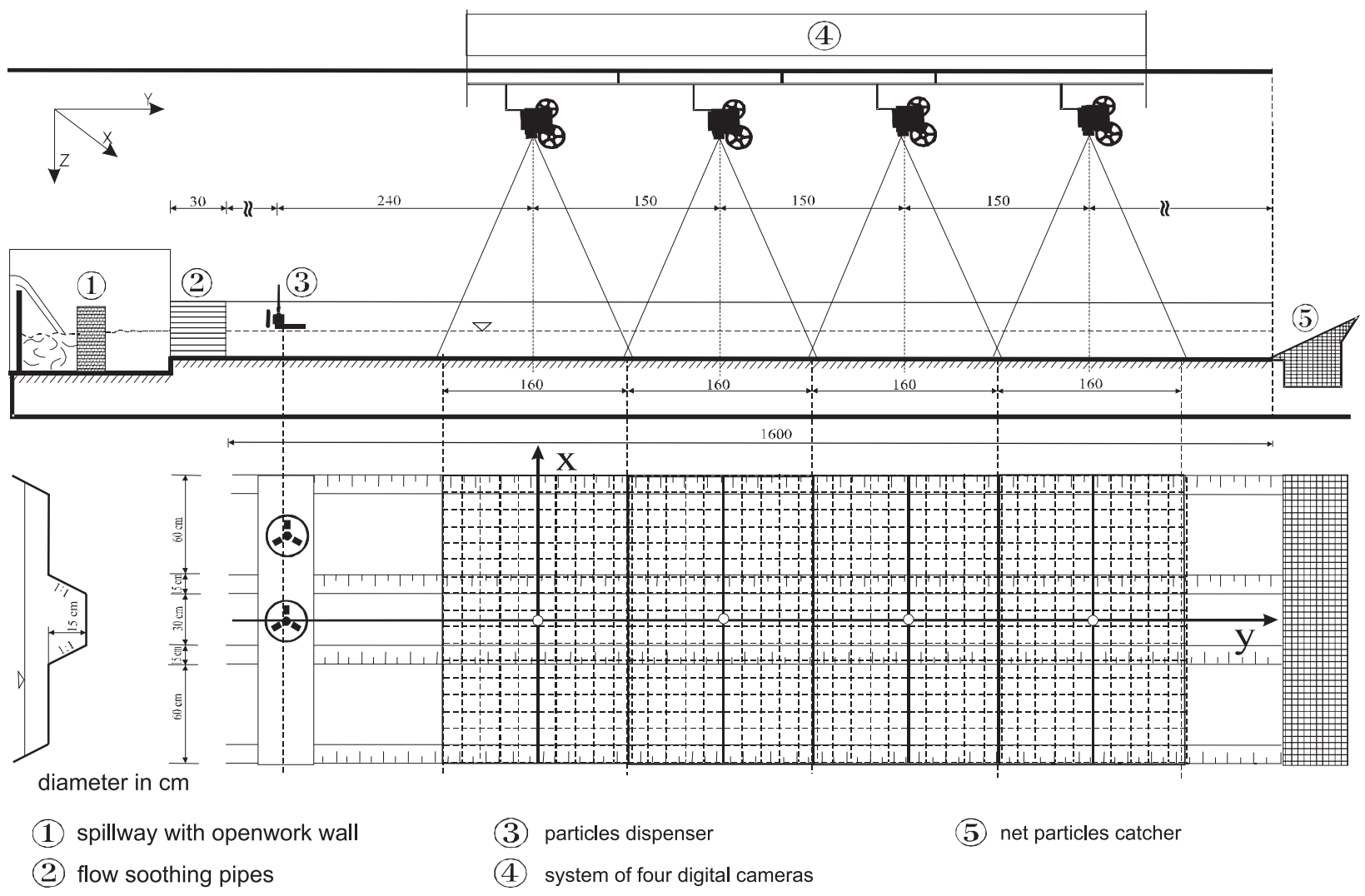

Fig. 2. Diagram of the laboratory setup for the video tracking of particles on the water surface

Table 1. Characteristics of the experiment

\begin{tabular}{llccccc}
\hline \multirow{5}{*}{ Experiment } & \multicolumn{1}{c}{ Batcher position } & $\begin{array}{c}\text { Dosing time } \\
t[\mathrm{~s}]\end{array}$ & $\begin{array}{c}\text { Water level in } \\
\text { the channel } \\
H[\mathrm{~m}]\end{array}$ & $\begin{array}{c}\text { Flow rate } \\
Q[\mathrm{l} / \mathrm{s}]\end{array}$ & $\begin{array}{c}\text { Average } \\
\text { velocity } \\
V[\mathrm{~m} / \mathrm{s}]\end{array}$ & $\begin{array}{c}\text { Number of } \\
\text { particles } \\
N\end{array}$ \\
\cline { 2 - 7 } & Left floodplain & 4.84 & & & 0.310 & 195 \\
& Main channel & 3.94 & 0.283 & 0.0805 & 0.380 & 195 \\
& Right floodplain & 5.00 & & & 0.300 & 195 \\
\hline
\end{tabular}


Krukowski, M., Siwicki, P. (2019). Primary analysis of the trajectory of floating particles in a compound channel. Acta Sci. Pol., Formatio Circumiectus, 18 (4), 37-47. DOI: http://dx.doi.org/10.15576/ASP.FC/2019.18.4.37

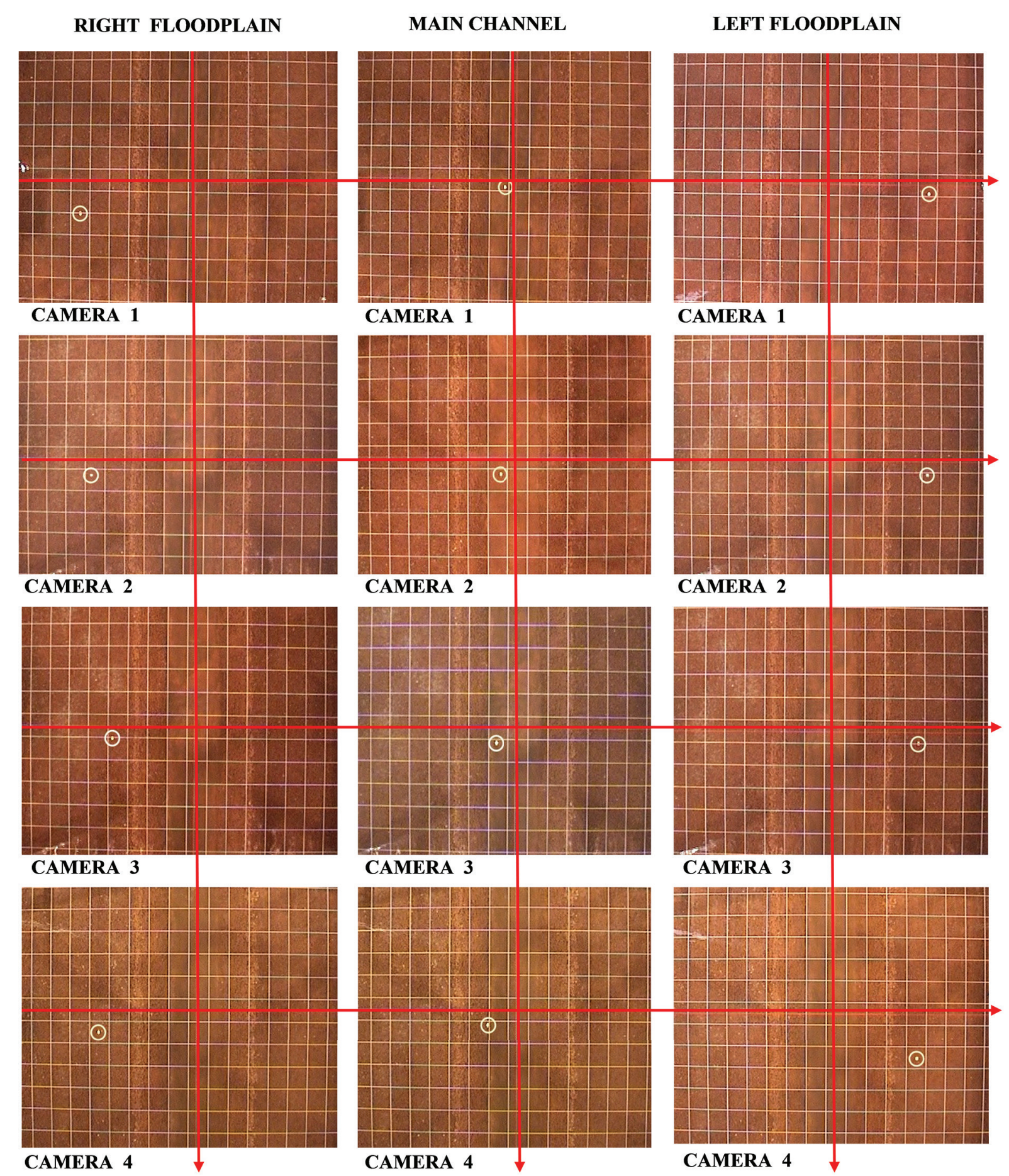

Fig. 3. Selected position of the particle recorded at a set time by cameras $1,2,3$ and 4 for the water level $H=0.283 \mathrm{~m}$ (first measuring area from above) 


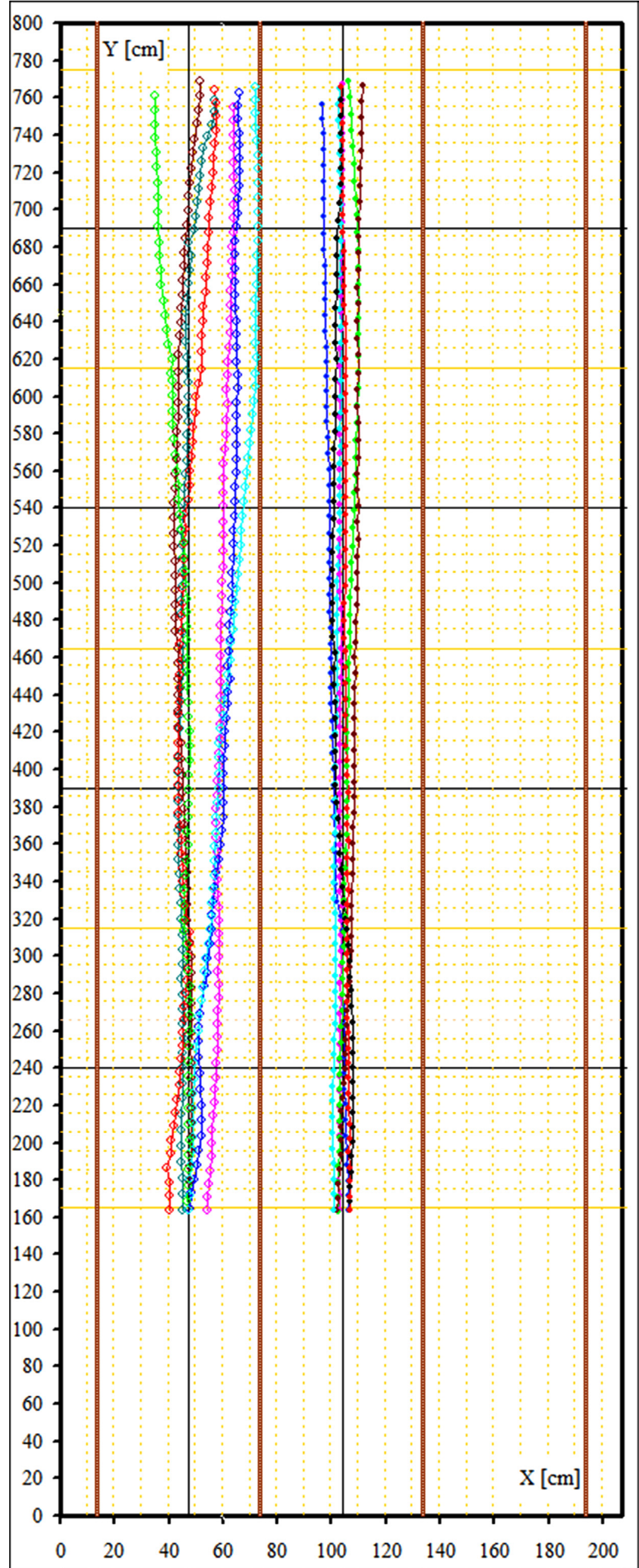

Fig. 4. Selected particle trajectories for the water level $H=0.283 \mathrm{~m}$ 


\section{RESEARCH RESULTS AND DISCUSSION}

In a homogeneous steady turbulent flow, the determined coefficient of turbulent diffusion $K_{i}$ characterizes the transport capacity of the flow and is associated with the second-order momentum - see: equation (9).

In the study of turbulence, the instantaneous and spatial characteristics of vortices formed in the flow were estimated. Such characteristics can be determined on the basis of Lagrange's autocorrelation function. These functions were calculated for selected particles, introduced both to the main channel and to the designated floodplain. The coordinates of these particles were determined every 0.04 seconds throughout the entire channel. The observation of selected particles made it possible to determine their trajectory in the surface zone of flowing water. The recorded positions of particles from the moment of their introduction to the test channel are shown in Figure 4. A tendency was observed for particles from the floodplain to approach the main channel. This is due to the large difference in water velocity in the main channel and the floodplain, and the momentum transfer between them. There is a limited momentum transfer zone between the main channel and floodplains (Guan et al., 2002) and probably when a particle reaches this area, it will change its trajectory. In the conducted experiments, some particles introduced into the floodplains flowed into the main riverbed. Selected curves illustrating the course of changes in the autocorrelation function for floating particles are presented for the main channel in Figure 5, and for floodplains in Figure 6.
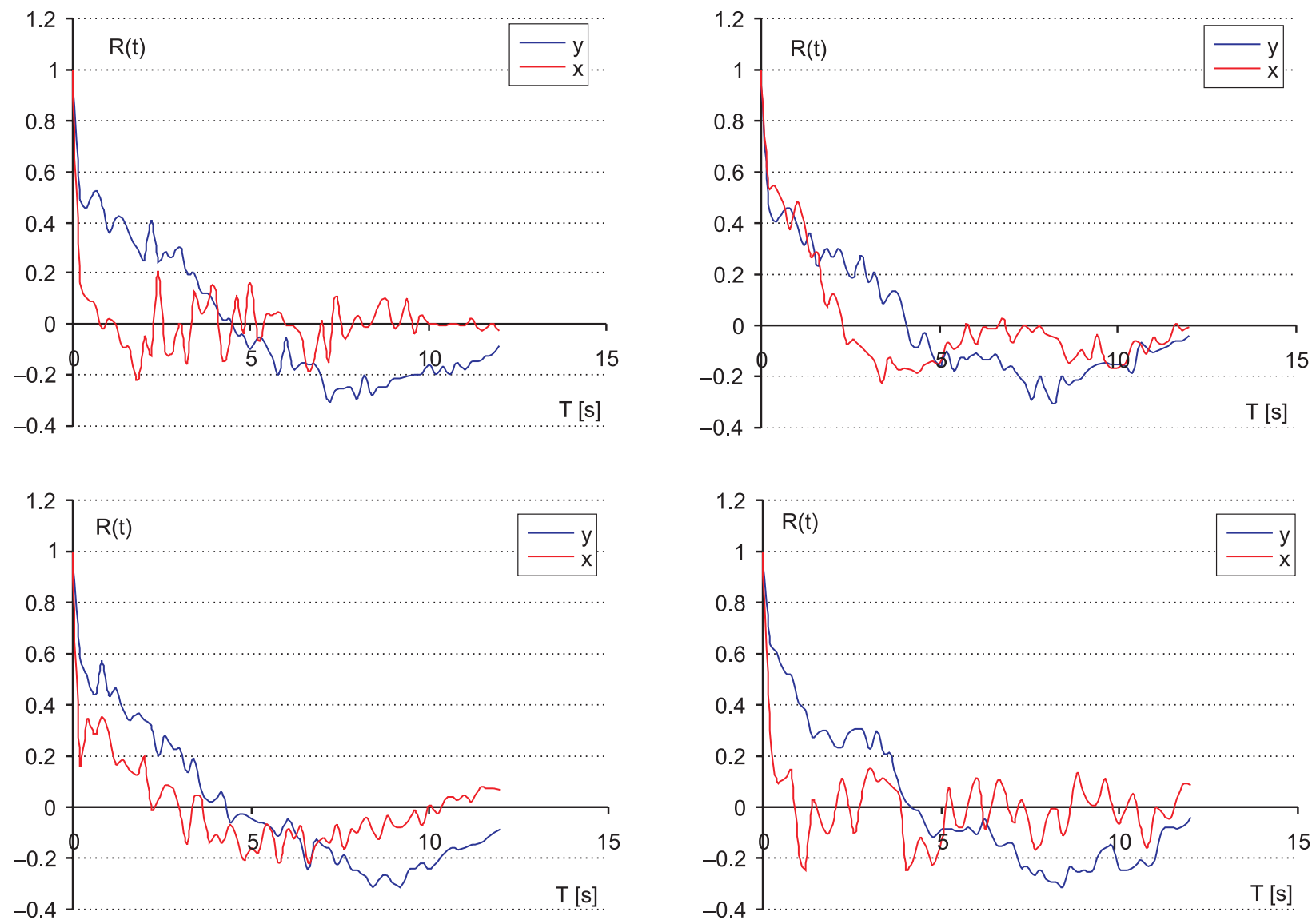

Fig. 5. Examples of Lagrangian autocorrelation function for the longitudinal and transverse velocity for selected particles released in the main channel at water level $H=0.283 \mathrm{~m}$ 

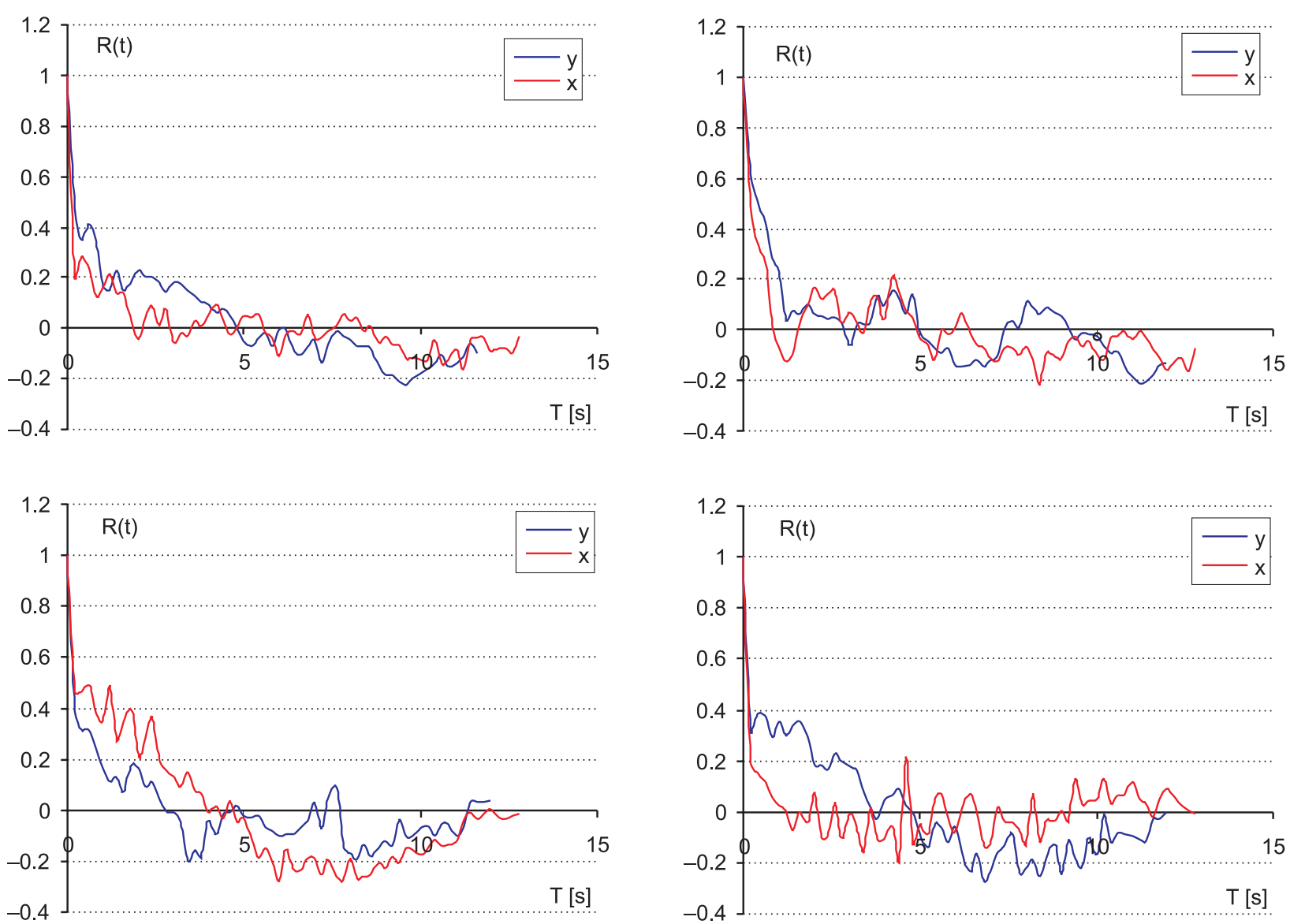

Fig. 6. Examples of Lagrangian autocorrelation function for the longitudinal and transverse velocity for selected particles released in left the floodplain at water level $H=0.283 \mathrm{~m}$

As follows from Figures 5 and 6, the values of autocorrelation functions drop quickly over time, and then oscillate irregularly around zero. Lagrange auto-correlation function reset times and length scales for the main channel take values from $1.0 \mathrm{~s}$ to $1.83 \mathrm{~s}$, and from $3.3 \mathrm{~cm}$ to $5.2 \mathrm{~cm}$, respectively. These scales within the floodplains range from $0.56 \mathrm{~s}$ to $1.12 \mathrm{~s}$, and from $1.3 \mathrm{~cm}$ to $3.4 \mathrm{~cm}$. respectively. It should be noted that these scales reach higher values in the main channel than in the floodplains.

The analysis of selected particle trajectories in the experiment provided the necessary data to determine the vortex length $L$ and turbulent diffusion coefficients $K$ in the floodplain and in the main channel in Lagrange's approach (see: Table 3). In the main channel, the vortex length values are two or three times greater than the vortex length $L_{E}$ values obtained using Euler's method. Also in the floodplain, vortex lengths calculated on the basis of Lagrange's functions are twice as large as those calculated for the Euler function (see: Table 2).

On the other hand, the values of diffusion coefficients in the main channel determined on the basis of the Lagrange autocorrelation function $K_{L}$ are also much higher than the diffusion coefficients calculated for the Euler function (see: Table 2 and Table 3). The situation in the floodplain is quite different; there, the values of turbulent diffusion coefficients in both calculation methods are closer to each other in relation to the calculation results from the main channel. This may indicate that, in the analysed case, the most intense process of mixing impurities in the surface zone occurs definitely in the floodplain area - rather than in the main channel. 
Table 2. Turbulence characteristics calculated on the basis of ADV probe measurements for the water level (Euler's approach) $H=0.283 \mathrm{~cm}$

\begin{tabular}{|c|c|c|c|c|c|}
\hline $\begin{array}{l}\text { Dosing } \\
\text { position }\end{array}$ & $\begin{array}{c}\bar{v} \\
{[\mathrm{~m} / \mathrm{s}]}\end{array}$ & $\begin{array}{r}\sigma / \bar{\nu} \\
{[-]}\end{array}$ & $\begin{array}{l}T_{E} \\
{[\mathrm{~s}]}\end{array}$ & $\begin{array}{c}L_{E} \\
{[\mathrm{~m}]}\end{array}$ & $\begin{array}{c}K_{E} \\
{\left[\mathrm{~m}^{2} / \mathrm{s}\right]}\end{array}$ \\
\hline \multirow{4}{*}{ 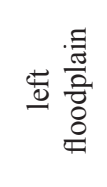 } & 0.387 & 0.076 & 0.391 & 0.150 & 0.00165 \\
\hline & 0.393 & 0.081 & 0.365 & 0.133 & 0.00136 \\
\hline & 0.396 & 0.088 & 0.445 & 0.150 & 0.00231 \\
\hline & 0.391 & 0.080 & 0.387 & 0.142 & 0.00155 \\
\hline \multirow{4}{*}{. } & 0.417 & 0.039 & 0.300 & 0.125 & 0.00083 \\
\hline & 0.415 & 0.039 & 0.303 & 0.126 & 0.00081 \\
\hline & 0.415 & 0.039 & 0.290 & 0.120 & 0.00079 \\
\hline & 0.412 & 0.038 & 0.291 & 0.122 & 0.00077 \\
\hline
\end{tabular}

Table 3. Turbulence characteristics calculated on the basis of particle trajectory analysis for the water level (Lagrange's approach) $H=0.283 \mathrm{~m}$

\begin{tabular}{|c|c|c|c|c|c|}
\hline $\begin{array}{l}\text { Dosing } \\
\text { position }\end{array}$ & $\begin{array}{c}\bar{v} \\
{[\mathrm{~m} / \mathrm{s}]}\end{array}$ & $\begin{array}{r}\sigma / \bar{v} \\
{[-]}\end{array}$ & $\begin{array}{l}T_{L} \\
{[\mathrm{~s}]}\end{array}$ & $\begin{array}{c}L_{L} \\
{[\mathrm{~m}]}\end{array}$ & $\begin{array}{c}K_{L} \\
{\left[\mathrm{~m}^{2} / \mathrm{s}\right]}\end{array}$ \\
\hline \multirow{7}{*}{ 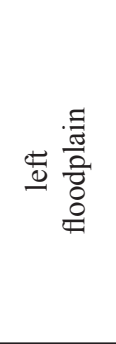 } & 0.374 & 2.16 & 0.62 & 0.232 & 0.00200 \\
\hline & 0.393 & 2.01 & 0.66 & 0.259 & 0.00208 \\
\hline & 0.379 & 2.39 & 1.09 & 0.413 & 0.00395 \\
\hline & 0.384 & 1.99 & 0.59 & 0.226 & 0.00280 \\
\hline & 0.370 & 2.17 & 1.12 & 0.422 & 0.00366 \\
\hline & 0.375 & 2.11 & 0.98 & 0.368 & 0.00310 \\
\hline & 0.386 & 1.91 & 0.56 & 0.216 & 0.00265 \\
\hline \multirow{7}{*}{ 志 } & 0.438 & 2.52 & 1.36 & 0.597 & 0.00602 \\
\hline & 0.424 & 2.26 & 1.00 & 0.424 & 0.00383 \\
\hline & 0.443 & 2.66 & 1.17 & 0.518 & 0.00551 \\
\hline & 0.427 & 2.58 & 1.45 & 0.619 & 0.00638 \\
\hline & 0.439 & 1.96 & 1.37 & 0.601 & 0.00471 \\
\hline & 0.431 & 2.70 & 1.34 & 0.591 & 0.00638 \\
\hline & 0.441 & 2.06 & 1.73 & 0.762 & 0.00628 \\
\hline
\end{tabular}

\section{CONCLUSION}

The Lagrange function is more related to individual particles of the fluid, which is related to the fact that it directly describes particles simulating the pollutants in the surface layer of water in this experiment. In addition, Lagrange's approach is formally simpler, but the data needed in this formal framework is more difficult to obtain experimentally (more difficult than obtaining the relevant data in Euler's framework).

Analysis of test results obtained in laboratory conditions using the PIV (Particle Image Velocimetry) technique based on particle trajectory (in Lagrange's approach), in comparison with the results of calculations of turbulence characteristics based on measurements with the ADV probe (in Euler's approach), presented in Tables 3 and 4, show significant differences between the results obtained. Specific parameters: turbulence intensity, vortex length, and values of turbulent diffusion coefficients, calculated on the basis of Lagrange's autocorrelation function, are much higher than the values calculated according to Euler's function. Only in the case of the calculated values of turbulent diffusion in the floodplain are the results of the same order in both presented methods. Their values indicate a greater intensity of mixing in the floodplains, in relation to the main channel.

\section{REFERENCES}

Elghobashi, S. (1994). On predicting particle-laden turbulent flows. Appl. Sci. Res., 52, 309-329.

Guan, Y., Altinakar, M. S., Krishnappan, B. G. (2002). Modeling of lateral flow distribution in compound channels. In Bousmar D., and Zech Y., River Flow 2002-Proceedings of the International Conference on Fluvial Hydraulics, Louvain-la-Neuve, Belgium, 169-175.

Hinze, J. O. (1975). Turbulence. New York: McGraw-Hill, Inc.

Knight, D.W., Yuen, K. W. H., Al-hamid, A. A. I. (1994) Boundary Shear Stress Distributions in Open Channel Flow. In Beven K. J., Chatwin P. C., and Millibank J. H., eds., Mixing and Transport in the Environment, Wiley, Chichester, 51-87.

Kozioł A., Krukowski, M. (2010). Modelling of flow capacity and mass transport in compound cross-section channel. Studia Geotechnica et Mechanica, XXXII, 1, 60-68.

Krukowski, M. (2005). Modelowanie migracji cząstek stałych w korycie o dwudzielnym przekroju. Rozprawa doktorska. Warszawa: SGGW.

Mols, B., Oliemans, V. A. (1998). A turbulent diffusion model for particle dispersion and deposition in horizontal tube flow. Int. J. Multipha. Flow, 24(1), 55-75.

Monin, A. S., Yanglom, A. M. (1971). Statistical Fluid Mechanics-Mechanics of Turbulence. Cambridge: MIT Press. 
Rowiński, P., Czernuszenko, W., Kozioł, A., Kubrak, J. (2002). Properties of a streamwise turbulent flow field in an open two-stage channel. Arch. Hydro Eng. Environ. Mech., 49, 37-57.

Rowiński, P., Czernuszenko, W., Krukowski, M. (2005). Migration of floating particles in a compound channel. Water Quality Hazards and Dispersion of Pollutants.
New York: Springer Science+Business Media, Inc., 121-141.

Sofialdis D., Prinos P. (1999). Turbulent flow in open channels with smooth and rough floodplains. Journal of Hydraulics Research, 37(5), 615-640.

Taylor, G. I. (1921). Diffusion by continuous movements. Proc. Lond. Math. Soc., 20, 196-212.

\section{WSTĘPNA ANALIZA TRAJEKTORII CZĄSTEK STAŁYCH W KORYCIE O DWUDZIELNYM PRZEKROJU POPRZECZNYM}

\section{ABSTRAKT}

\section{Cel pracy}

Celem przeprowadzonych badań było określenie parametrów zdolności transportowej strumienia za pomocą współczynników dyfuzji turbulentnej z wykorzystaniem techniki obrazowej i porównanie ich ze współczynnikami uzyskanymi w wyniku pomiaru sondą pomiarową ADV w korycie o przekroju złożonym.

\section{Materiały i metody}

Badania modelowe wykonano na fizycznym betonowym modelu prostoliniowego odcinka koryta z symetrycznymi terenami zalewowymi o złożonym trapezowym przekroju poprzecznym. Na modelu wykonano badania ruchu cząstek wykorzystano cyfrową technikę rejestracji obrazu z analizą ruchu dozowanego wskaźnika (cząstek stałych) (PIV - Particle Image Velocimetry), umożliwiającą wyznaczenie podstawowych parametrów charakteryzujących proces ich transportu w przypowierzchniowej warstwie wody w korycie.

\section{Wyniki i wnioski}

Wstępna analiza wyników badań uzyskanych w warunkach laboratoryjnych przy wykorzystaniu techniki PIV (Particle Image Velocimetry) na podstawie trajektorii cząstki (w ujęciu Lagrange'a) i porównaniu wyników obliczeń charakterystyk turbulencji na podstawie pomiarów sondą ADV (w ujęciu Eulera), pokazują znaczne różnice pomiędzy otrzymanymi wynikami. Określone parametry: intensywność turbulencji, długości wirów i wartości współczynników dyfuzji turbulentnej obliczone na podstawie funkcji autokorelacyjnej Lagrange'a są większe niż wartości obliczone według funkcji Eulera.

Słowa kluczowe: trajektoria cząstki pływającej, koryto o dwudzielnym przekroju poprzecznym, współczynnik dyfuzji turbulentnej 